\title{
A necropsy-based descriptive study of dairy cow deaths on a Colorado dairy
}

\author{
C. S. McConnel, ${ }^{* 1}$ F. B. Garry, ${ }^{*}$ J. E. Lombard, ${ }^{\dagger} \dagger$ J. A. Kidd, ${ }^{*}$ A. E. Hill, ${ }^{*}$ and D. H. Gould ${ }^{*}$ \\ *Integrated Livestock Management, Colorado State University, Fort Collins 80523 \\ †USDA:APHIS:VS, Centers for Epidemiology and Animal Health, 2150 Centre Ave., Bldg. B, Fort Collins, CO 80526-8117
}

\begin{abstract}
Increasing levels of dairy cow mortality pose a challenge to the US dairy industry. The industry's current understanding of dairy cow mortality is reliant upon descriptions largely based on producer or veterinary assumptions regarding cause of death without the benefit of detailed postmortem evaluations. A thorough necropsy is a superior tool for establishing a cause of death, except for cases involving euthanasia for traumatic accidents or severe locomotor disorders. Information provided from a necropsy examination would be most valuable if it were categorized and combined with cow health information in a complete postmortem evaluation designed to guide future management decisions. The objective of this study was to describe dairy cow deaths on a Colorado dairy over a 1-yr period and explore classification systems for necropsy findings that might inform management actions aimed at reducing dairy cow mortality. Throughout the study period a thorough necropsy examination was performed on every cow that died. Based upon this examination each death was characterized by a proximate cause (i.e., the most likely immediate cause of the death). Each proximate cause of death was then categorized using 3 alternate schemes founded on generalized etiologic principles and influenced by previous clinical history and treatments. These schemes included the broad categories commonly used for classifying findings within a review of literature related to dairy cow mortality, a diagnostic scheme used within the problem-oriented veterinary medical record, and an analysis focusing on the primary physiologic system derangement for each death. A total of 2,067 cows were enrolled during the study period of which 1,468 cows freshened, 507 cows were sold, and 94 cows died, resulting in a mortality risk of 6.4 deaths per 100 lactations at risk. The distribution of deaths by parity was significantly different from the herd distribution at the end of study with the largest percentage of death present in parity $\geq 4$. Postmortem findings attributable
\end{abstract}

Received July 1, 2008.

Accepted December 23, 2008.

${ }^{1}$ Corresponding author: craigmcc@colostate.edu to a specific cause of death were present for all but 4 of the 94 deaths. Assignment of the proximate causes of death to categories within the 3 alternate schemes provided a means for classifying necropsy findings and causes of death with different levels of detail. Creating categories with more selective groupings may provide a means for capturing specifics related to deaths that can be used to guide management decisions.

Key words: mortality, necropsy, dairy, cow

\section{INTRODUCTION}

Increasing levels of dairy cow mortality pose a challenge to the US dairy industry. The USDA:APHIS:VS National Animal Health Monitoring System (NAHMS) Dairy 2007 survey reported that $5.7 \%$ of dairy cows ( $\sim 520,000$ cows $)$ die on-farm across the country each year, a significant increase from $4.8 \%$ in the January 2002 inventory, and from 3.8\% in the January 1996 inventory (USDA, 2007b). These rising mortality levels represent a problem both in terms of financial losses and compromised animal welfare (Thomsen and Houe, 2006). An important first step in combating this problem lies in more clearly defining the reasons that cows die. Determining the cause of death provides invaluable information for preventing future deaths and improving herd health. However, relatively few US dairy operations utilize necropsies in an effort to determine the cause of cow death. The NAHMS Dairy 2007 study reported that necropsies were performed on only $13 \%$ of operations ( $\sim 9,750$ operations) and only $4.4 \%$ of dead dairy cows $(\sim 23,000$ cows; USDA, 2007a). Without the information provided by a necropsy, determining the cause of death is often dependent upon producer perceptions.

A literature review identified 19 studies between 1965 and 2006 that focused on dairy cow mortality in countries with relatively intensive dairy production (Thomsen and Houe, 2006). Although 10 of the 19 studies provided information about causes of death, none of the diagnoses were founded on necropsy examination. Only a single study discriminated between cows that were killed and those that died unassisted (Thomsen et al., 2004). Categories used to describe the deaths were 
relatively uniform across studies and included accidents, calving disorders, digestive disorders, locomotor disorders, metabolic disorders, udder/teat disorders, other known reasons, and unknown reasons (Thomsen and Houe, 2006). Similar descriptors for causes of death were used within the NAHMS Dairy 2007 survey, which documented the percentage of cow deaths due to calving problems (15.2\%); scours, diarrhea, or other digestive problems $(10.4 \%)$; euthanasia due to lameness or injury $(20.0 \%)$; mastitis (16.5\%); respiratory problems $(11.3 \%)$; poison $(0.4 \%)$; lack of coordination or severe depression $(1.0 \%)$; other known reasons $(10.2 \%)$; and unknown reasons (15.0\%) (USDA, 2007b). Although these categorical groupings are commonly used there is no information in the literature to validate that these groupings are useful for directing management changes or that they are used for such a purpose.

Thomsen and Houe's (2006) review demonstrated a range of mortality levels from 1 to $5 \%$ between studies, with wide variations in the percentage of deaths ascribed to specific categories. In fact, there is no information within the literature that assesses whether death losses were accurately assigned to these categories. Excluding a few outliers, accidents generally accounted for 5 to $13 \%$ of deaths, udder/teat disorders for 8 to $25 \%$ of deaths, and metabolic disorders for 8 to $18 \%$ of deaths (Thomsen and Houe, 2006). When killed cows were grouped independently, locomotor disorders accounted for the single largest percentage (40\%) of such deaths (Thomsen et al., 2004). The limitations of such surveys led to a significant percentage of deaths allotted to categories such as "other known reasons" (10 to $70 \%$ of deaths) or "unknown reasons" (4 to $46 \%$ of deaths), nomenclature that does not delineate causality or suggest preventative strategies (Thomsen and Houe, 2006).

Based on the findings from past studies focusing on dairy cow mortality, several suggestions for future studies have been recommended. These include recording a measure of the mortality level, place and year of study, study design, sampling method, sample size, and method of death (Thomsen and Houe, 2006). Information regarding causes of death is also warranted in an effort to more precisely establish specific diagnoses and associated risk factors. The current study hypothesized that a necropsy examination is superior to owner perception for establishing a proximate cause of death. The objective of this study was to describe dairy cow deaths on a Colorado dairy over a 1-yr period and explore necropsy-based classification systems that might inform management actions aimed at reducing dairy cow deaths.

\section{MATERIALS AND METHODS}

This observational study was conducted from March 1, 2005, through February 28, 2006, on a high-producing (approximately 11,500 kg of milk/cow per year), commercial dairy in northern Colorado. The dairy had completed an expansion 5 yr before the study to achieve a stable inventory of approximately 1,450 Holstein cows (lactating and dry). Lactating cows were predominantly housed in freestall barns using sand bedding with a single dry lot devoted to cows with reproductive problems and late-lactation, low-producing individuals. The average SCC was 250,000 cells $/ \mathrm{mL}$ and cows were milked 3 times a day. Approximately $40 \%$ of cows received bST. The hoof care program involved the treatment of animals observed with lameness and twice-yearly maintenance trimming. Nutritional management included the use of a TMR, routine milk urea nitrogen testing, forage testing, and ration formulation based on production and stage of lactation. The average dry period was $57 \mathrm{~d}$ with dry cows separated into faroff, close-up, and maternity pens consisting of dry lots bedded with straw. Cows were moved to the close-up pen 3 wk before their predicted freshening date and to the multiple-animal maternity pen approximately $1 \mathrm{wk}$ before predicted freshening. Heifers and mature cows were grouped together within the close-up and maternity pens. Fresh cows were penned separately from hospital cows, and first-lactation cows were grouped separately from mature cows. Approximately 28 fulltime staff participated in milking and cow management activities, with training sessions 1 to 2 times per year to cover protocols related to milking, calving, and fresh cow monitoring. Routine veterinary services were provided by the Colorado State University (CSU) College of Veterinary Medicine. Operational management included the use of on-farm computer systems to track cow and herd level data.

Biographical information was collected on firstlactation and greater cows and included source (homeraised vs. purchased), age, parity, freshening date, and where applicable, death date, days in milk at time of death, and type of death (euthanasia vs. unassisted). The percentages of dairy cow mortalities by source and parity were determined by dividing the number of cows that died during the study by the number of dairy cows (both dry and in milk) present on the operation at the end of the study (March 1, 2006). The proportions of deaths by season, type of death, source, and parity were compared using a chi-square test for equal proportions (PROC FREQ SAS, version 9.1, SAS Inst. Inc., Cary, NC). The type of death by season and source of animals 
by parity was also compared using a chi-square test. For comparative purposes the mortality percentage (i.e., the number of dead cows during the study period divided by the number of dairy cows present on the operation on March 1, 2006), mortality rate (i.e., the number of cows dying out of the total number of cow years at risk during the year), and mortality risk (i.e., the number of cows dying divided by the number of cows that calved during the year) were calculated. The sold percentage, rate, and risk were similarly calculated for those cows that were sold during the year.

Throughout the study period an examination was performed on every cow that died. The examination included a necropsy except in cases where obvious traumatic accidents caused the death. When possible, CSU veterinarians performed antemortem clinical evaluations on animals to be killed. Before a necropsy examination the producer's (owner's) perception of the proximate cause of death (i.e., the most likely immediate cause of the death) was recorded and subsequently compared against specific necropsy findings such as those listed in Figure 1. Necropsy examinations were performed as soon as possible after death and within $24 \mathrm{~h}$. The majority of necropsies were performed at the Colorado State University Veterinary Diagnostic Laboratory (CSUVDL) by pathologists. A small percentage of necropsies were performed at the dairy by CSU veterinarians when carcass transport was impractical. A single veterinarian with formal postgraduate training in necropsy techniques (Severidt et al., 2002) provided oversight and was ultimately responsible for documenting all necropsies. The submission of appropriate tissue or biologic samples for further diagnostics was discretionary and based on necropsy findings when additional insight was warranted to confirm or determine the cause of death. The proportion of deaths that were correctly defined by the producer relative to a necropsy examination was compared using a chi-square test.

Each death was characterized by a proximate cause based upon the necropsy examination. Each proximate cause of death was then categorized using 3 schemes founded on generalized etiologic principles and influenced by previous clinical history and treatments. These schemes included the broad categories that were used for classifying findings from the mortality study review (Thomsen and Houe, 2006) and which most closely align with descriptors used in on-farm databases, a diagnostic scheme used within the problem-oriented veterinary medical record (Osborne, 2005), and an analysis focusing on the primary physiologic system derangement for each death. Review categories included accidents, calving disorders, digestive disorders, locomotor disorders, metabolic disorders, udder/teat disorders, other known reasons, and unknown reasons. The veterinary medical record scheme was based on the mnemonic acronym DAMN-IT with categories as follows: Degenerative; Anomalous, autoimmune; Metabolic; Nutritional, neoplastic; Inflammatory (infectious or noninfectious), immune mediated, iatrogenic, idiopathic; Traumatic, and toxic. The physiologic classification system analysis recorded each death in terms of the most severely affected organ or body system felt to be primarily responsible for or affected by the proximate cause of death.

Placement of cases within the various schemes relied on necropsy findings and any pertinent antemortem historical influences, such as health problems, trauma, or production issues, that were documented by dairy employees or attending veterinarians. As an example, there were 5 animals for which the proximate cause of death was attributed to a torn or ruptured uterus. Of these, 2 were damaged from either a uterine prolapse or torsion with no history of intervention before the damage occurred. These 2 cases were therefore categorized as calving disorders (review classification), trauma (DAMN-IT scheme), and uterus (physiologic classification). The other 3 cases were attributed to a history of inappropriate or inadequate handling of dystocias. These 3 cases were then categorized as calving disorders (review), iatrogenic (DAMN-IT), and uterus (physiologic).

For those animals that calved during the study period, an analysis of survival after calving was performed using the PROC LIFETEST procedure of SAS. Only cows that calved during the study period were included in this survival analysis to avoid a biased selection of proven survivors at the onset of the study. Days from calving to death were included in the model, and the cows were stratified according to parity $(1,2,3$, or 4 and older). Differences in the beginning of the survival curves were evaluated using the Peto and Wilcoxon tests, whereas differences in the tail of the curves were evaluated using the log-rank test, with a $P$-value of $\leq 0.05$ used to establish significant differences (Hosmer and Lemeshow, 1999). Animals that were sold for dairy purposes or slaughter before the end of the study or were alive at the end of the study were right censored.

\section{RESULTS}

The participating dairy's cow (lactating and dry) inventory on March 1, 2005, was 1,465 and remained stable throughout the study, with a population of 1,462 cows on September 1, 2005, and 1,463 cows on March 1, 2006. During the study period 2,067 cows were enrolled of which 1,468 cows freshened, 507 cows were sold for slaughter, and 94 cows died. Comparisons of the proportions of deaths by type of death (euthanasia vs. unassisted) and season demonstrated no differences within 


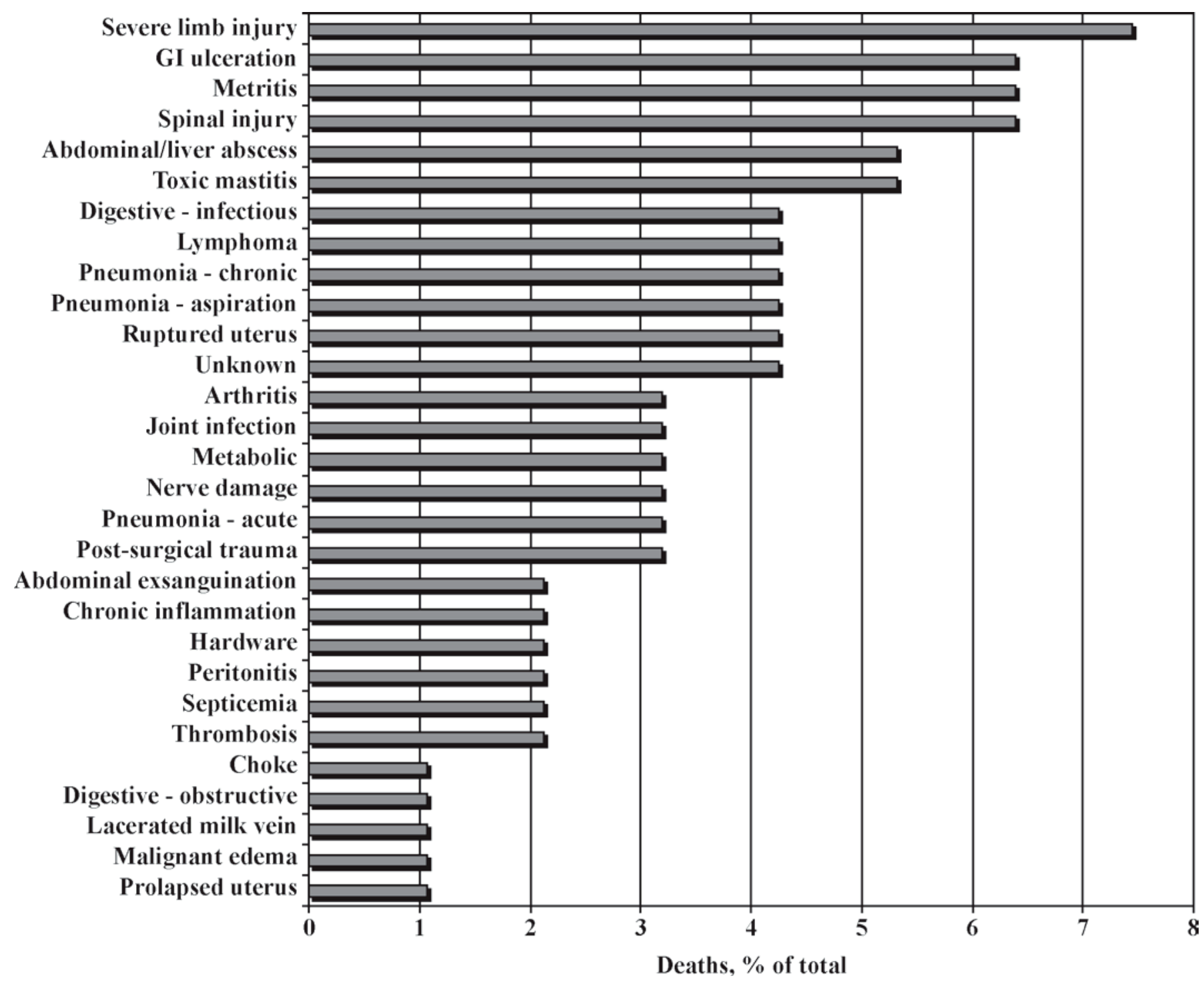

Figure 1. Postmortem findings representing the proximate cause of death for 94 cows that died between March 1, 2005, and February 28, 2006, on a Colorado dairy.

each category ( $P$-values of 0.30 and 0.61 , respectively; Table 1). Similarly, the distribution of deaths by source (home-raised vs. purchased) was not significantly different from the herd distribution $(P$-value 0.12$)$; however, the distribution of deaths by parity was significantly different with the largest percentage of deaths present in parity $\geq 4(P$-value $<0.001$; Table 2$)$. The type of death was independent of season $(P$-value $=0.95)$; however, parity was dependent upon the source, with the majority of home-raised cattle $(86 \%)$ in their first or second lactations $(P$-value $<0.001)$. The various measures of mortality were comparable with a mortality percentage of $6.4 \%$, a mortality rate of 6.4 deaths per 100 cow years at risk, and a mortality risk of 6.4 deaths per 100 lactations at risk. The sold percentage
(34.7\%), sold rate (34.7 cows sold per 100 cow years at risk), and sold risk (34.5 cows sold per 100 lactations at risk) were similarly equivalent.

Necropsies were performed on 83 of the 94 dead cows, with 72 of the necropsies performed at the CSUVDL and 11 by veterinarians on the dairy. No necropsies were performed on 11 of the cows because the antemortem history and cow examination revealed severe pathology due to traumatic accidents such as a broken leg or a lacerated milk vein, negating the requirement for a necropsy to establish the proximate cause of death. Of the cows not necropsied, 9 were killed in response to severe musculoskeletal damage. Adjunctive diagnostics such as histopathology, bacteriology, or virology were pursued in $51 \%$ of all cases $(48 / 94)$ or $58 \%$ 
Table 1. Descriptive statistics and Chi-square analysis of 94 dairy cow deaths by type of death and season

\begin{tabular}{llccc}
\hline Category & Description & Deaths, n & Deaths, \% & $\begin{array}{c}\text { Chi-square } \\
\text { P-value }\end{array}$ \\
\hline \multirow{2}{*}{ Type of death } & Killed & 42 & 44.7 & 0.30 \\
\multirow{3}{*}{ Season } & Unassisted death & 52 & 55.3 & 0.61 \\
& Spring: Mar, Apr, May & 18 & 19.2 & \\
& Summer: June, July, Aug & 26 & 27.7 & \\
& Autumn: Sept, Oct, Nov & 24 & 25.5 & \\
& Winter: Dec, Jan, Feb & 26 & 27.7 & \\
\hline
\end{tabular}

$(48 / 83)$ of cases that were necropsied. These additional diagnostics were necessary for establishing a proximate cause of death in $6 \%(6 / 94)$ of all cases or $7 \%(6 / 83)$ of necropsied cases.

The producer's perception of the cause of death was recorded before each necropsy examination. This perception was deemed correct if it matched the proximate cause of death as defined by the primary necropsy findings. For example, if the producer classified the cause of death as "pneumonia" and the necropsy defined the cause of death as "bronchopneumonia" the producer's perception was correct. However, if the perceived cause of death was recorded as "metritis," whereas the postmortem findings might have included metritis but demonstrated that the immediate cause of death was toxic coliform mastitis, the producer was incorrect. This level of detail was considered appropriate for establishing a correct diagnosis so that an accurate representation of the underlying health issue would be documented to help direct future endeavors at lessening mortality. The percentage of correct observations is recorded in Table 3 for each review grouping. Compared with the $96 \%$ of cases $(90 / 94)$ where the cause of death was determined by postmortem examination, the producer was correct only $55 \%(52 / 94)$ of the time $(P$-value $<0.001)$. If accidents $(100 \%$ correct) and locomotor disorders $(83 \%$ correct) were removed from the total, the producer was correct only $41 \%$ (29/70) of the time. Similarly, if only killed animals were taken into account, the producer was correct $79 \%(33 / 42)$ of the time; however, for those animals that died an unassisted death the producer's assessment was correct only $37 \%(19 / 52)$ of the time.
As shown in Figure 1, the proximate causes of death could be represented by several relatively specific necropsy findings. However, this type of classification had limited utility in that it was highly detailed and failed to group deaths into potentially manageable subsets. Proximate causes of death were therefore categorized based on causal principles that might be affected to mitigate unfavorable outcomes (Table 3 ). The most generic categorization scheme involved that established within the review of literature related to dairy cow mortality (Thomsen and Houe, 2006). Alternative categories based on the DAMN-IT scheme and physiologic system derangements provided slightly more specific groupings. As can be seen in Table 3, each review group typically encompassed several groups within the other categories. However, the DAMN-IT and physiologic category groups varied with respect to each other. For example, the review group "accidents" equated to a single DAMN-IT group ("trauma") that required 3 physiologic groupings ("esophagus," "musculoskeletal," and "udder") to capture the same information. On the other hand, the single review group "locomotor disorders" related to only one physiologic group ("musculoskeletal") but required 2 DAMN-IT groupings ("inflammation infectious" and "inflammation noninfectious").

Of the 1,468 cows that calved during the study a total of 62 cows died (4.2\%). Probability of survival after calving for cows that calved during the study is presented in Figure 2. The survival curves for different parities were compared and indicated that differences were present both at the beginning (Wilcoxon $P$-value $<0.001$, Peto $P$-value $<0.001)$ and toward the end $(\log$ -

Table 2. Descriptive statistics and Chi-square analysis of 94 dairy cow deaths by source and parity

\begin{tabular}{llcccc}
\hline Category & Description & Cows, $n$ & Deaths, $n$ & Mortality, ${ }^{1} \%$ & $\begin{array}{c}\text { Chi-square } \\
P \text {-value }\end{array}$ \\
\hline Source & Home-raised & 851 & 47 & 5.5 & 0.12 \\
\multirow{3}{*}{ Parity } & Purchased & 612 & 47 & 7.7 & $<0.001$ \\
& 1 & 645 & 28 & 4.3 & \\
& 2 & 393 & 24 & 6.1 & \\
& 3 & 245 & 16 & 6.5 & \\
\hline
\end{tabular}

${ }^{1}$ Mortality percentage is calculated as the number of deaths divided by the herd inventory on March 1, 2006, per respective category. 
Table 3. Three classification schemes for documenting causes of death in 94 dairy cows ${ }^{1}$

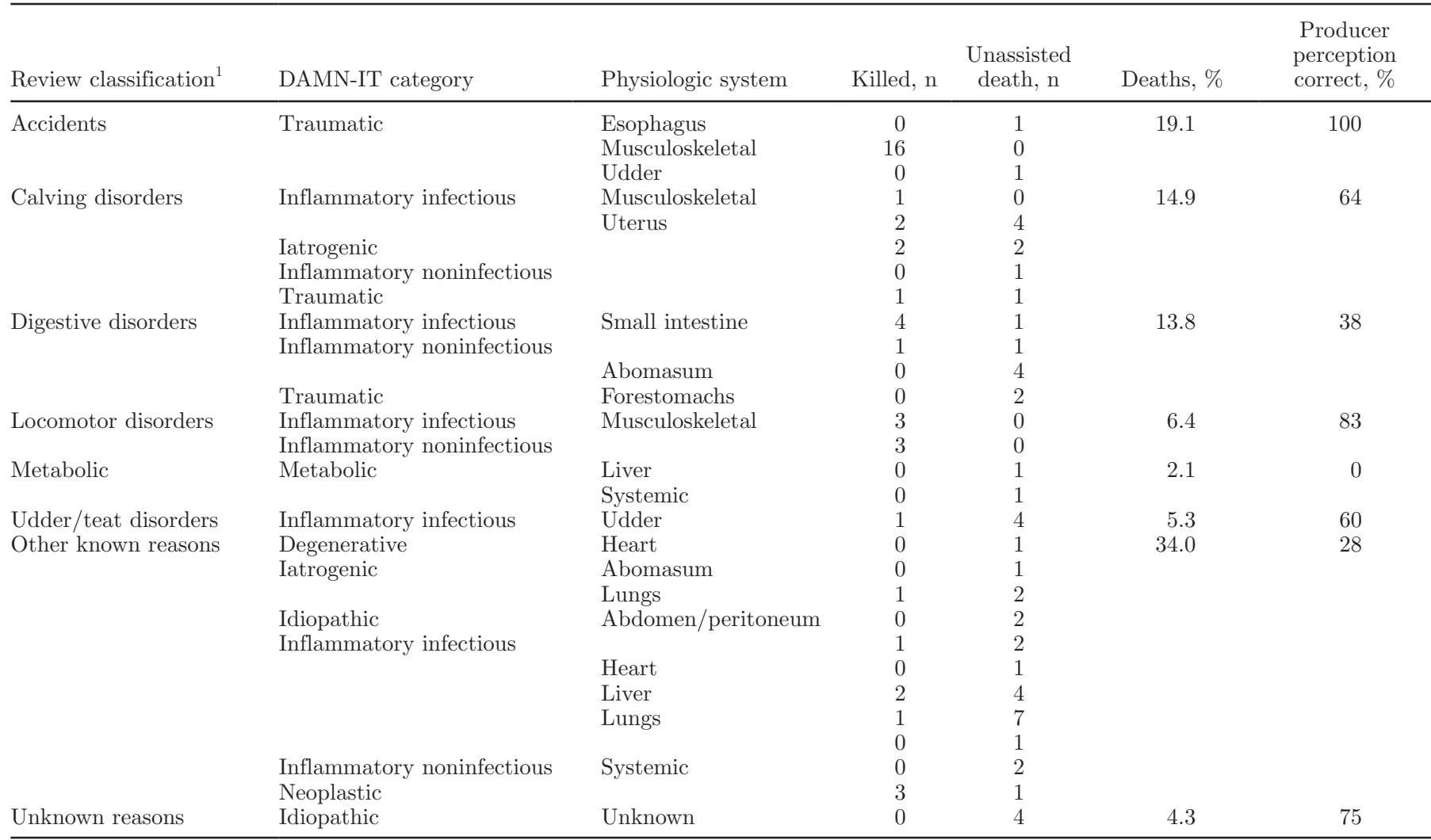

${ }^{1}$ The number of cows that died (unassisted or killed) is recorded along with the percentage of deaths reflected by each review classification. The percentage of deaths for which the producer's perception of the cause of death was correct relative to that established by postmortem evaluation is also shown.

${ }^{2}$ Thomsen and Houe (2006).

rank $P$-value $<0.001)$ of a lactation. Overall results for the study showed that $21 \%(20 / 94), 36 \%(34 / 94)$, and $45 \%(42 / 94)$ of deaths occurred by 6,15 , and $30 \mathrm{~d}$, respectively, after calving (Figure 3 ). For younger cows (parities 1 and 2), 40\% (21/52) of deaths occurred by 30 d after calving. For older cows (parities 3 and greater), $50 \%(21 / 42)$ of deaths occurred by $30 \mathrm{~d}$ after calving.

\section{DISCUSSION}

Reducing dairy cow mortality is an important challenge for the US dairy industry. Cow mortality represents the most costly form of permanent removal from the herd, is a significant indicator of cow well-being, and appears to have occurred with increasing frequency over the last decade. Yet the dearth of literature specific to the subject suggests that it has not been adequately addressed. The industry's current understanding of dairy cow mortality is reliant upon descriptions largely founded on assumptions without the benefit of detailed postmortem evaluations. Consequently, the current literature tends toward analyses of factors associated with mortality levels rather than describing cow death relative to specific necropsy findings. These studies do not elucidate cause and effect and have limited utility for directing management decisions aimed at enhancing well-being and minimizing death rates.

Efforts to deal with this challenge require an understanding of when cows are most prone to die, what the predominant detrimental influences and specific pathologies are that underlie cow death, and how best to record and analyze mortalities to effectively direct management. A high proportion of deaths have been shown to occur during the first 15 to $30 \mathrm{~d}$ after calving (Milian-Suazo et al., 1988; Faye and Perochon, 1995; Menzies et al., 1995; Stevenson and Lean, 1998; Thomsen et al., 2004). Additionally, the distribution of deaths during the first $30 \mathrm{~d}$ of lactation is skewed, with the highest proportion occurring during the first few days after calving (Thomsen et al., 2004). The results from this current study confirm these findings, in that $45 \%$ of the total deaths occurred within the first $30 \mathrm{~d}$ after calving and nearly half of those deaths occurred within the first $6 \mathrm{~d}$ of lactation (Figure 3 ). This is a 


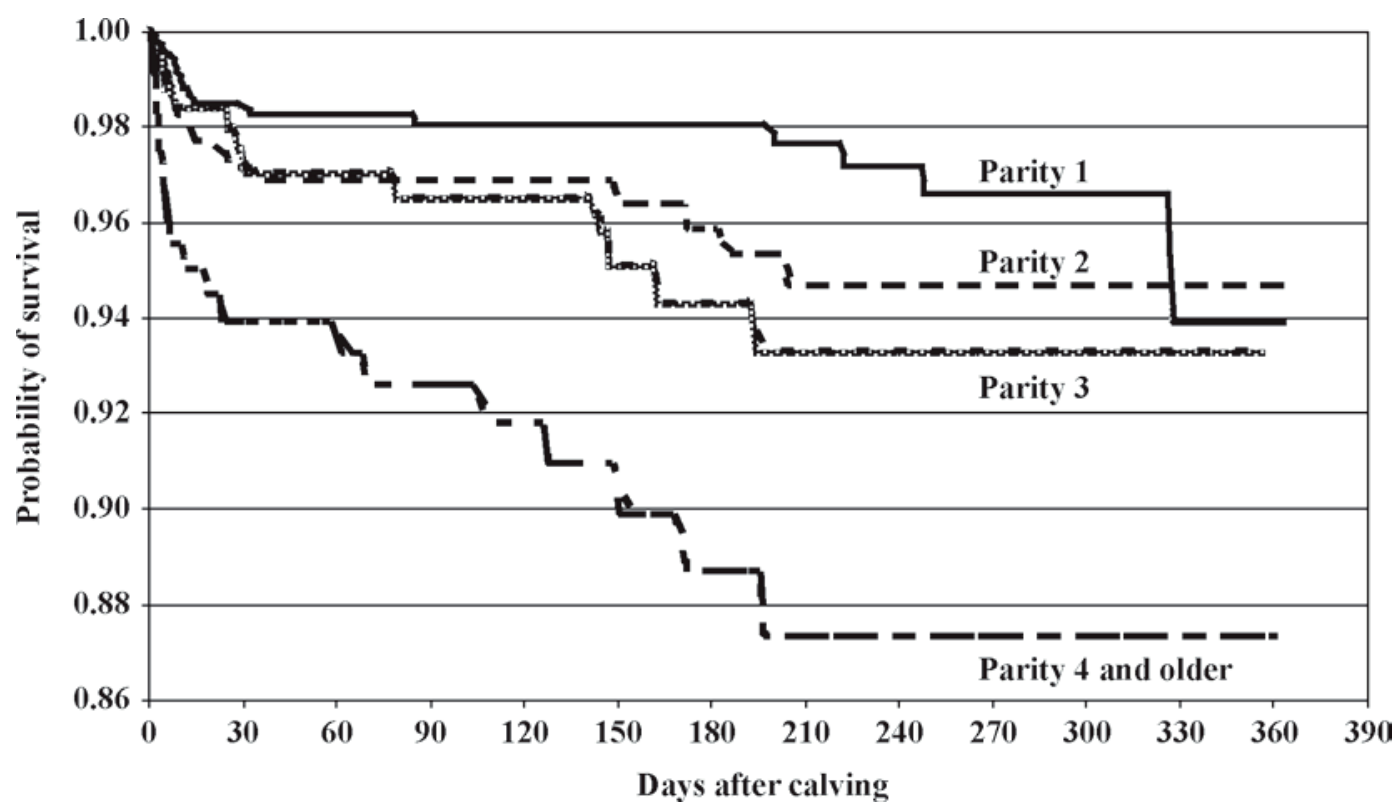

Figure 2. Probability of survival after calving for cows that calved between March 1, 2005 and February 28, 2006, by parity on a Colorado dairy.

likely result of the periparturient period's association with health problems including locomotor disorders (Shanks et al., 1981; Markusfeld, 1993; Green et al., 2002). Furthermore, additional studies have found a higher mortality among older cows (Faye and Perochon, 1995; Dematawewa and Berger, 1998; Stevenson and Lean, 1998; Thomsen et al., 2004; Miller et al., 2008). The present study supports this association (Table 2; Figure 2), which may be partly explained by increased incidences of certain diseases such as hypocalcemia, ketosis, and retained fetal membranes with increased parity (Markusfeld, 1993; Grohn et al., 1998; Houe et al., 2001).

Understanding why cow mortality occurs can be very useful in preventing further occurrences. To this end it is helpful to know causes of death in conjunction with timing and occurrence rates. However, capturing information regarding why cows die presents a substantial

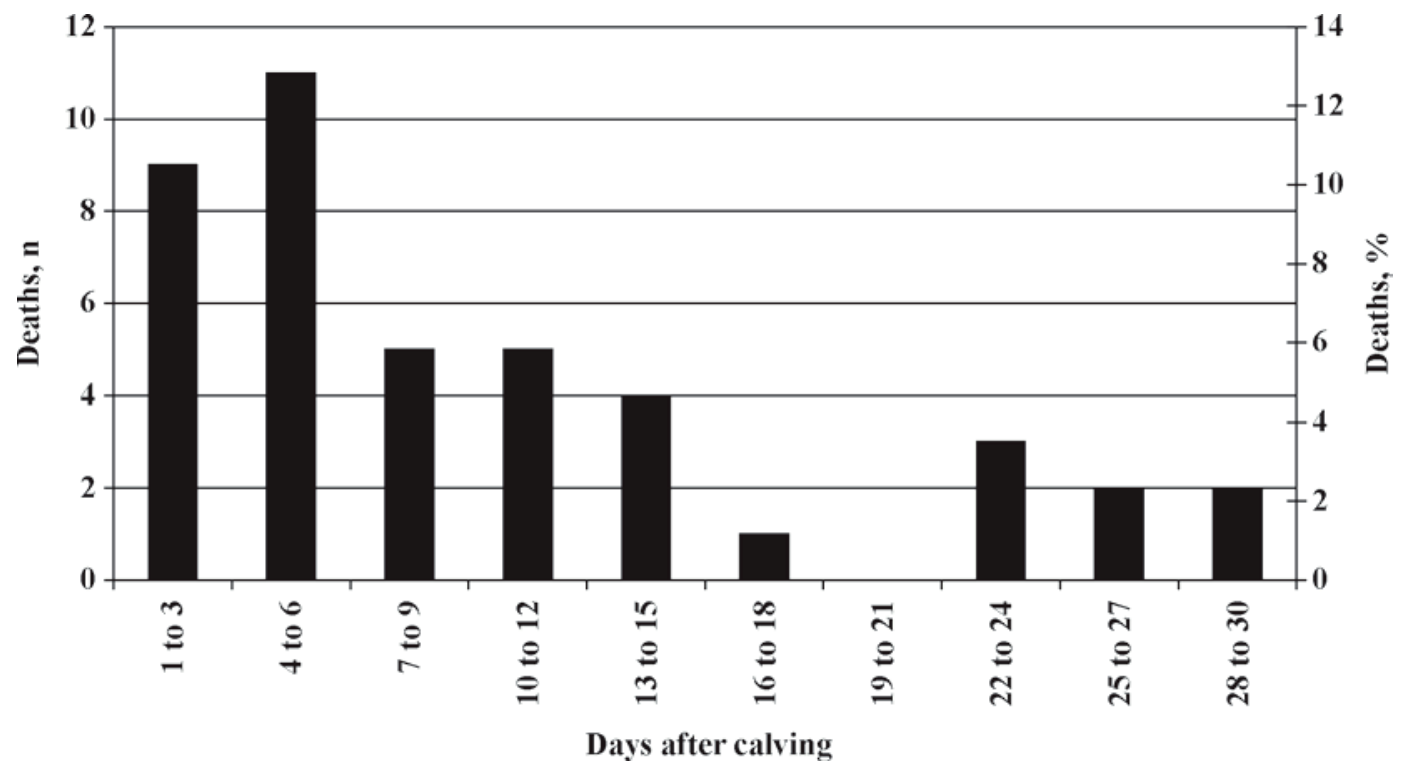

Figure 3. The number and percent of deaths in the first $30 \mathrm{~d}$ of the lactation for cows that died between March 1, 2005 and February 28 , 2006 on a Colorado dairy. 
challenge. Thomsen and Houe's review of dairy cow mortality found that only 10 of 19 studies gave some information on causes of death (Thomsen and Houe, 2006). The level of detail was variable and most studies had a relatively large proportion of causes classified as "unknown" (16 to 46\%). More recently, the NAHMS Dairy 2007 survey classified $15.0 \%$ of cow deaths as being due to unknown reasons (USDA, 2007b). Only when killed cattle are considered independently does the proportion of unknown causes substantially lessen (Thomsen et al., 2004), as might be expected because euthanasia is often preceded by a diagnosis. None of the 19 studies documented in the review utilized necropsies to determine the causes of death (Thomsen and Houe, 2006). Consequently, perceptions based solely on antemortem histories played a significant role in determining recorded causes of death. The present study suggests that a producer's perception of cause of death can be seriously flawed ( $45 \%$ incorrect overall), particularly when dealing with animals dying an unassisted death (63\% incorrect).

This study was founded on the premise that a detailed necropsy examination would provide the best information for establishing causes of death. Although the study was conducted on a single dairy, many of the observations can be generalized because they consider whether commonly used descriptors of mortality are meaningful sources of information on which to base management decisions. As can be seen, different methods for classifying necropsy findings and causes of death can provide very different levels of detail. Individual deaths can be defined by specific findings (Figure 1) but this level of detail is difficult to analyze for underlying herd-level problems and is itself limited in its account of the sequence of events that lead to the death. Although the proximate cause of death provided useful insight into underlying pathology, many cases involved multiple pathologic lesions that inevitably contributed to overall morbidity and undoubtedly influenced the final cause of death. For example, within this study an animal died of embolic, suppurative pneumonia that originated from hepatic abscessation with vena caval extension and sepsis. Although the animal ultimately died from pulmonary failure that may or may not have been treatable, the origins of her morbidity stemmed from the disease process that resulted in liver abscesses.

Categorization of this case resulted in "lungs" (physiologic), "inflammation infectious" (DAMN-IT), and "other known reasons" (review) The generic "other known reasons" category within the review classification (Table 3) provides no useful information for understanding what ultimately led to a death. Nonetheless, on-farm databases have historically depended on capturing relevant information regarding dead cows in broad categories such as those within the review system. Although such a system of categories lacks the ability to define specific proximate causes of death, it does provide an avenue for grouping similar etiologies within databases that were not developed to deal with the specifics of cow mortality. Creating categories with more selective groupings such as those represented by the DAMN-IT and physiologic schemes may provide a means for capturing specifics related to deaths that can be analyzed as whole. However, the use of such categories would require a change in the way current databases are constructed and utilized. Necropsy findings are essential for defining the ultimate or proximate cause of death but must be viewed in whole and within the context of preceding events that precipitated the death.

The information gained from a necropsy examination must be recorded in a format that can be used for formulating management strategies. Pertinent historical information relative to a cow's death should be integrated into any system that attempts to record why cows die. It has been shown that record systems that only allow a single reason for death or culling provide only partial documentation of the reason for removal (Bascom and Young, 1998). Simply capturing descriptors of the proximate cause of death fails to acknowledge that an individual death is often the end result along a continuum of failures. This provides an additional challenge as most record systems on US dairies are focused on reproductive and milk production performance and are primarily used by producers to evaluate the current status and performance of animals as well as to generate "to-do" lists. Health events are either not monitored, are poorly defined (e.g., categories such as illness, lame, or digestive are not sufficiently characterized to allow analysis of specific problems; or a specific disease such as hemorrhagic bowel syndrome is identified as HBS, BLDGUT, CLOST in the records), or are not recorded at all. Thus, the records are not configured to facilitate analysis of prior events that result in a current condition; in other words, it is difficult to assess cause and effect.

This study focused principally on using necropsy findings to categorize causes of death. Combining necropsy examination findings with other pertinent information in a complete postmortem evaluation would ideally provide a meaningful degree of detail when assessing causes of death, regardless of variations inherent in necropsy techniques and in the use of ancillary testing. Although the current study focused on performing necropsies on all but the most obviously traumatic deaths, the practical application of necropsy examinations may necessitate a more targeted approach as determined by 
personnel and disposal constraints. Although there are instances (accidents, locomotor disorders, euthanasia) where the information gained may not warrant the cost and effort required to perform a necropsy, this study suggests that there are numerous other cases where a necropsy could provide additional insight into the actual cause of death. Based on the frequency with which producers may incorrectly classify deaths, necropsies may provide necessary insight if health records are to be populated with useful and correct information. Although the costs incurred from necropsies vary depending on who performs the task, whether it be trained in-house personnel or a private veterinarian, the cost to benefit ratio will be directly related to the application of the necropsy-based information to operational management. The challenge remains in integrating the postmortem details in a comprehensive and useful strategy for combating rising levels of dairy cow mortality. To be successful, any efforts to manage increasing mortality levels must view the problem as a whole. Focusing attention on those cows most at risk for disease and death, tracking and recording health events, and establishing proximate causes of death based on necropsy findings must be combined with an understanding of those facets of management that influence poor outcomes. Ideally, record system templates should be constructed that are consistent across operations and describe specific causes of death within the context of historical influences. Records of this quality would allow for easy determination of deaths over a period of time and could guide implementation of management practices or facility designs that ultimately reduce dairy cow mortality.

\section{ACKNOWLEDGMENTS}

This research was funded in part by the Colorado State University Agricultural Experiment Station.

\section{REFERENCES}

Bascom, S. S., and A. J. Young. 1998. A summary of the reasons why farmers cull cows. J. Dairy Sci. 81:2299-2305.
Dematawewa, C. M., and P. J. Berger. 1998. Genetic and phenotypic parameters for 305-day yield, fertility, and survival in Holsteins. J. Dairy Sci. 81:2700-2709.

Faye, B., and L. Perochon. 1995. Mortality of dairy cows in an ecopathological survey in Brittany / La mortalite des vaches laitieres dans l'enquete ecopathologique Bretagne. Vet. Res. $26: 124-131$.

Green, L. E., V. J. Hedges, Y. H. Schukken, R. W. Blowey, and A. J. Packington. 2002. The impact of clinical lameness on the milk yield of dairy cows. J. Dairy Sci. 85:2250-2256.

Grohn, Y. T., S. W. Eicker, V. Ducrocq, and J. A. Hertl. 1998. Effect of diseases on the culling of Holstein dairy cows in New York State. J. Dairy Sci. 81:966-978.

Hosmer, D. W., and S. Lemeshow. 1999. Applied Survival Analysis: Regression Modeling of Time to Event Data. John Wiley \& Son Inc., New York, NY

Houe, H., S. Ostergaard, T. Thilsing-Hansen, R. J. Jorgensen, T. Larsen, J. T. Sorensen, J. F. Agger, and J. Y. Blom. 2001. Milk fever and subclinical hypocalcaemia - An evaluation of parameters on incidence risk, diagnosis, risk factors and biological effects as input for a decision support system for disease control. Acta Vet. Scand. 42:1-29.

Markusfeld, O. 1993. Parturition disease complex of the high-yielding dairy cow. Acta Vet. Scand. Suppl. 89:9-15.

Menzies, F. D., D. G. Bryson, T. McCallion, and D. I. Matthews. 1995 A study of mortality among suckler and dairy cows in Northern Ireland in 1992. Vet. Rec. 137:531-536.

Milian-Suazo, F., H. N. Erb, and R. D. Smith. 1988. Descriptive epidemiology of culling in dairy cows from 34 herds in New York state. Prev. Vet. Med. 6:243-251.

Miller, R. H., M. T. Kuhn, H. D. Norman, and J. R. Wright. 2008. Death losses for lactating dairy cows in herds enrolled in dairy herd improvement test plans. J. Dairy Sci. 91:3710-3715.

Osborne, C. A. 2005. 'DAMN-IT' acronym offers practical diagnostic aid. Pages 44-46 in DVM: The Newsmagazine of Veterinary Medicine. Vol. 36

Severidt, J. A., D. J. Madden, G. L. Mason, F. B. Garry, and D. H. Gould. 2002. Dairy Cattle Necropsy Manual. Integrated Livestock Management, Colorado State University. http://www.cvmbs. colostate.edu/ilm/proinfo/necropsy/notes/index.html.

Shanks, R. D., A. E. Freeman, and F. N. Dickinson. 1981. Postpartum distribution of costs and disorders of health. J. Dairy Sci. 64:683688.

Stevenson, M. A., and I. J. Lean. 1998. Descriptive epidemiological study on culling and deaths in eight dairy herds. Aust. Vet. J. $76: 482-488$.

Thomsen, P. T., and H. Houe. 2006. Dairy cow mortality. A review. Vet. Q. 28:122-129

Thomsen, P. T., A. M. Kjeldsen, J. T. Sorensen, and H. Houe. 2004 Mortality (including euthanasia) among Danish dairy cows (19902001). Prev. Vet. Med. 62:19-33.

USDA. 2007a. Dairy 2007, Part 1: Reference of Dairy Cattle Health and Management Practices in the United States, 2007. USDAAPHIS-VS, CEAH, Fort Collins, CO.

USDA. 2007b. Dairy 2007, Part II: Changes in the U.S. Dairy Cattle Industry, 1991-2007. USDA-APHIS-VS, CEAH, Fort Collins, CO. 